\title{
A fairer EU asylum system
}

\author{
The on-going European refugee crisis requires a concerted response across EU member states, \\ including policy reform.
}

By the end of 2016, more than 65 million people were forcibly displaced worldwide as a result of conflict or persecution ${ }^{1}$. This number includes more than 10 million newly displaced people - equivalent to 20 new displacements for every minute in 2016. More than half of the world's refugees come from three countries: Syria, Afghanistan and South Sudan, where on-going conflicts have forced millions to flee their homes.

Although the vast majority of refugees (84\% in 2016) are hosted by developing countries $^{1}$, tensions about the influx of refugees, especially as a result of the Syrian crisis, have risen in Europe. This has been particularly the case since 2015 , which saw more than 1.2 million asylum applications across European Union member states twice as many as the previous year ${ }^{2}$. The vast majority of refugees have been entering the European Union through its southeast borders, mainly Greece and Italy.

The massive increase in asylum seekers over the past three years has created a significant challenge for the union, the individual host countries, and primarily for refugees themselves. The current system of regulating asylum seeker applications in the European Union - the Dublin Regulation - allocates asylum seekers based on the country of first entry. As a result, high numbers of refugees are caught in limbo in countries such as Greece and Italy that have been struggling to cope with massive numbers of arriving refugees.

Surveys repeatedly show that the majority of citizens in each EU member state do not want to see the number of asylum seekers increase in their countries. This attitude is disheartening - many of these countries experienced mass displacement in the Second World War - but it isn't the whole picture. The refugee crisis has been a test for the identity of the European Union, as national interests conflict with collective EU responsibility.

Bansak, Hainmueller and Hangartner (article no. 0133) surveyed 18,000 voters from 15 different EU countries, trying to gauge their preferences regarding the allocation of asylum seekers: do Europeans prefer the current system, which places the majority of the burden on the country of first entry, or a system where asylum seekers are distributed proportionally across

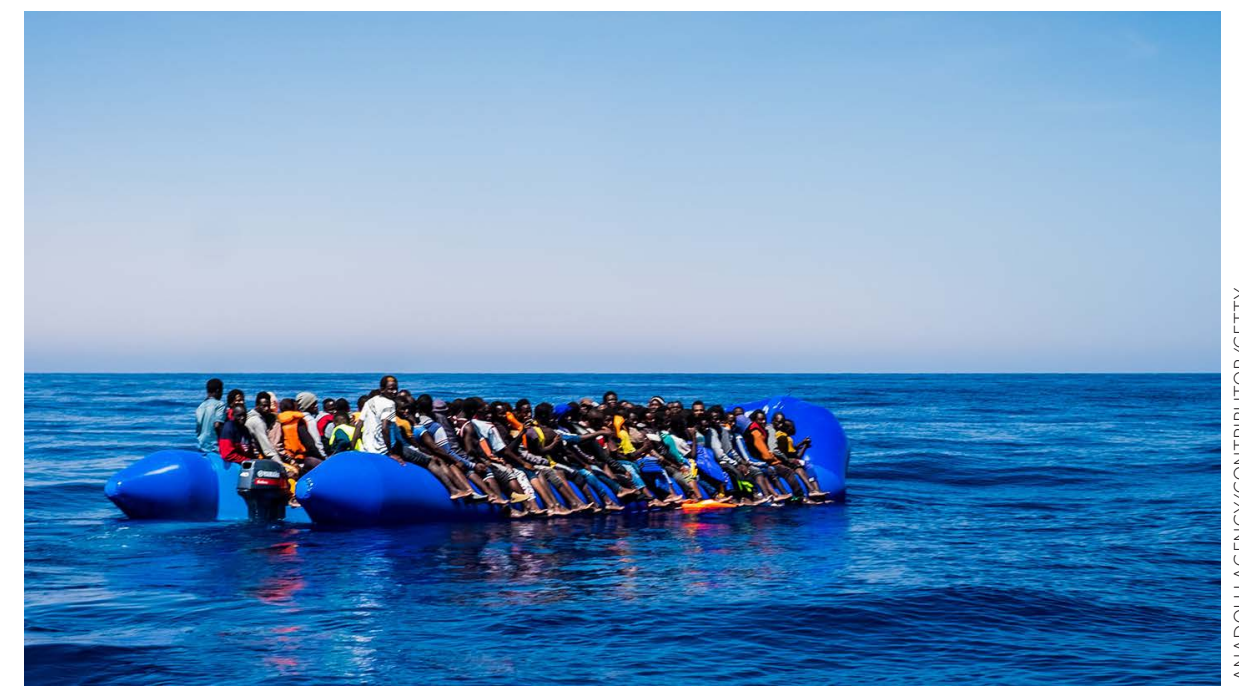

EU member states? Respondents across all 15 countries overwhelmingly favoured proportional allocation of refugees over the Dublin status quo. The picture was more complex for a subset of participants who were told of the consequences of each choice (by including the exact number of refugees their country would need to take on): support for proportional allocation was reduced and for citizens of the United Kingdom, Poland and the Czech Republic preferences were reversed, such that they supported the status quo over proportional allocation. However, proportional allocation did remain the preferred choice for the majority of respondents at 56\%, as compared to $27 \%$ for the status quo. Although consequences clearly matter, most Europeans are driven by a sense of fairness when considering the allocation of asylum applications.

A version of proportional allocation has been adopted by the European Commission in the context of a two-year emergency relocation scheme that started in September 2015. To alleviate the significant pressure from Greece and Italy, the European Commission proposed to relocate 160,000 asylum seekers from those two countries to other member states using quotas. The decision was not uncontroversial politically, however. Hungary and Slovakia have taken recourse to the European Court of Justice to try and abolish the quotas. Hungary and Poland refused to take any refugees. The
Czech Republic only took on a dozen before dropping out of the scheme. This refusal prompted the European Commission to initiate infringement proceedings towards the three countries in June 2017.

The emergency relocation scheme expires on 23 September and it has shown very limited success: up until 9 June 2017, and only a few months before the end of the scheme, just over 22,500 asylum seekers had been relocated out of the intended $160,000^{3}$. In a press release in March 2016, the European Commission cited "the lack of political will among Member States" as the key reason for the very slow progress ${ }^{4}$. Although governments seem to exhibit a lapse in solidarity, European citizens according to the survey Bansak et al. conducted are driven primarily by a sense of fairness when considering the allocation of asylum seekers within the union. To provide adequate humanitarian protection to refugees, policy reform is necessary, but also politically possible: a proportional allocation system would be likely to meet with approval by the majority of EU member states citizens.

\footnotetext{
References

1. Global Trends: Forced Displacement in 2016 (United Nations High Commissioner for Refugees, 2017)

2. Asylum Statistics (Eurostat, 2017); http://go.nature.com/2tddnnE

3. Relocation and Resettlement (European Commission, 2017); http://go.nature.com/2u87sMQ

4. Relocation and Resettlement: EU Member States Urgently Need to Deliver (European Commission, 2016); http://go.nature. com/2sdoisk
} 